\title{
Acidity at different sites in the proximal duodenum of normal subjects and patients with duodenal ulcer
}

\author{
J. RHODES AND C. J. PRESTWICH \\ From the Departments of Medicine and Radiology, The Royal Infirmary, Cardiff
}

EDITORIAL COMMENT The gradient of acidity from stomach to distal duodenum is of considerable physcological interest and this paper presents the results of the first extensive experimental investigation of this gradient.

Rhodes, Apsimon, and Lawrie (1966) have recently measured $p \mathrm{H}$ in the duodenal bulb for long periods using two glass electrodes. By this method it is possible to maintain the distal electrode within the duodenal bulb for long periods but its exact position in the bulb cannot be determined. Over short periods of time, however, the electrode can be located accurately by radiological methods. In this paper we describe the results of short-term observations on duodenal $p \mathrm{H}$ in normal subjects and patients with duodenal ulcer.

\section{SUBJECTS}

Eleven normal subjects and 13 with duodenal ulcer were studied. They were all adult males, and their ages are given in Table I. The normal subjects had no history of epigastric discomfort. All the subjects with ulcer had had recent barium meals which showed a duodenal ulcer, the ulcer being in the duodenal bulb in all except one subject (D.U.13) who had a post-bulbar ulcer; they were all having ulcer symptoms at the time of the investigation.

\section{APPARATUS}

A composite tube was used (Figure 1) which consisted of

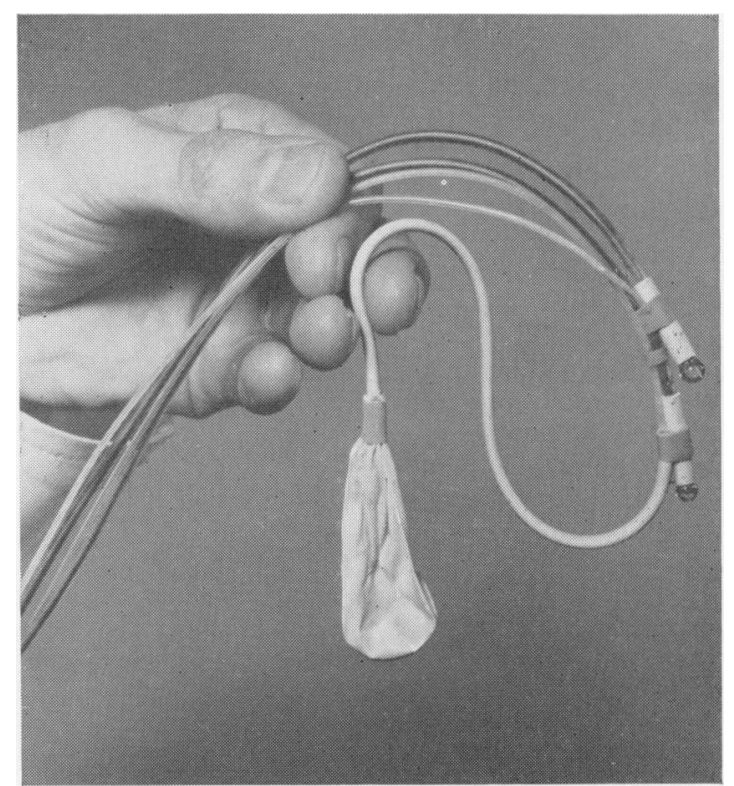

FIG. 1. The tube used for measurement of $\mathrm{pH}$ at different sites in the duodenum.

TABLE I

DETAILS OF SERIES STUDIED

\section{Normal}

Patient no.
Age
Recording time (min.)
after meal

Mean antral $p \mathrm{H}$
Duodenal Ulcer

\begin{tabular}{lllllllllllll}
\hline 1 & 2 & 3 & 4 & 5 & 6 & 7 & 8 & 9 & 10 & 11 & 12 & 13
\end{tabular}

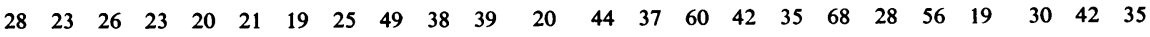

$\begin{array}{llllllllllllllllllllllll}40 & 90 & 45 & 60 & 60 & 55 & 70 & 60 & 70 & 35 & 55 & 60 & 120 & 105 & 60 & 60 & 50 & 40 & 48 & 55 & 85 & 50 & 55 & 40\end{array}$

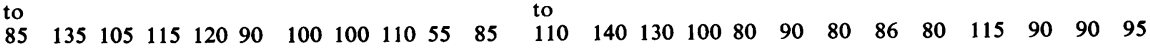

$\begin{array}{llllllllllllllllllllllll}3.2 & 2.4 & 2.5 & 2.6 & 2.0 & 1.8 & 1.8 & 1.9 & 3.7 & 2.6 & 2.3 & 1.85 & 2.1 & 1.8 & 1.8 & 2.4 & 1.3 & 1.9 & 1.6 & 1.6 & 1.25 & 1.8 & 2.0 & 1.25\end{array}$ 509 
two glass electrodes (Cambridge Instrument Co. Ltd.) separated by $2.5 \mathrm{~cm}$., a reference lead from the calomel electrode, a tube connected to the terminal rubber bag which could be filled with water and Gastrografin, and a narrow tube which opened near the proximal electrode. This last tube was used to inject Gastrografin into the duodenal bulb before taking a radiograph.

\section{PROCEDURE}

The tube was passed after the nasal cavity had been anaesthetized with cocaine. When the electrodes were in the duodenum the subject ate a standard meal of $1 \mathrm{~g}$. of minced meat and $2 \mathrm{~g}$. of mashed potatoes per kilogram of body weight, followed by a cup of tea.

The $p \mathrm{H}$ was recorded in the second part of the duodenum, from different sites in the duodenal bulb, and at the end of the investigation from the gastric antrum. Throughout this period the patient lay on the $x$-ray table, prone and tilted to the right, a position which facilitates gastric emptying. At least every five minutes the position of the electrodes was checked using the image intensifier and a note of their position was made on the $p \mathrm{H}$ tracing. The radiologist occasionally found it difficult to determine whether the electrode was just proximal or distal to the pylorus but at such times the record of $p \mathrm{H}$ served as a check. Proximal to the pylorus the $p \mathrm{H}$ is about 2 and steady whereas distal to the pylorus wide fluctuations occur in the $p \mathrm{H}$ (Rhodes et al., 1966). It was always possible to confirm the position of the electrode radiographically by careful positioning of the patient. In addition, three or four films were taken after $1 \mathrm{ml}$. of Gastrografin had been injected into the duodenal bulb (Fig. 2); the records for the subsequent five minutes were not used for analysis of $p \mathrm{H}$. The films served as a permanent record and were later used to confirm the position of the electrodes. While $p \mathrm{H}$ was recorded, the terminal bag was emptied to limit to-and-fro movement of the electrodes.

$p$ H RECORDS For a period of about 45 minutes, one hour after the meal, i.e., while gastric emptying was taking place, $p \mathrm{H}$ was recorded continuously from both electrodes on a Sanborn recorder (model 64A). At the end of the investigation the electrodes were calibrated with buffered solutions of $p \mathrm{H} 3$ and 8 .

The records chosen for analysis of duodenal $p \mathrm{H}$ were those obtained while the electrodes were in a constant position within the duodenum; the electrode was taken to be stationary if it appeared to be in the same place when viewed several times on the image intensifier. Most of the records were from the distal electrode. The position of the electrodes in relation to the duodenal bulb was confirmed from a film taken while $p \mathrm{H}$ was recorded in that position; the electrode was described as being in the gastric antrum, the base, middle, distal half or apex of the duodenal bulb, the upper, middle, or lower third of the second part of the duodenum. It was not recorded as a distance distal to the pylorus because of the variable length of the duodenal bulb in different subjects. Records were not obtained from all sites in all patients. If the duodenal $p \mathrm{H}$ was neutral, without any fluctuations, it was observed

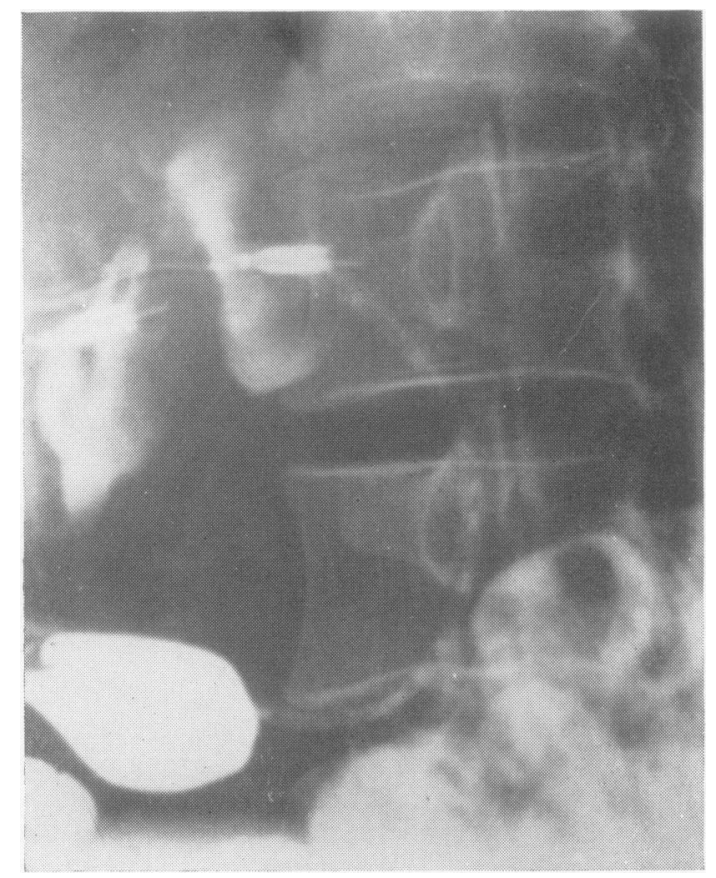

FIG. 2. A radiograph which shows Gastrografin in the duodenal bulb. The proximal electrode is in the gastric antrum and the distal in the bulb.

that gastric emptying was not taking place and these records were discarded.

The $p \mathrm{H}$ records were analysed in two ways, viz., (a) the total area below the records was measured, using a planimeter, and the average $p \mathrm{H}$ calculated by dividing this area by the distance over which the measurement was made, and $(b)$ the total duration of time spent below $\mathrm{pH}$ $2,2 \cdot 5,3,4$, and 6 was measured on each record.

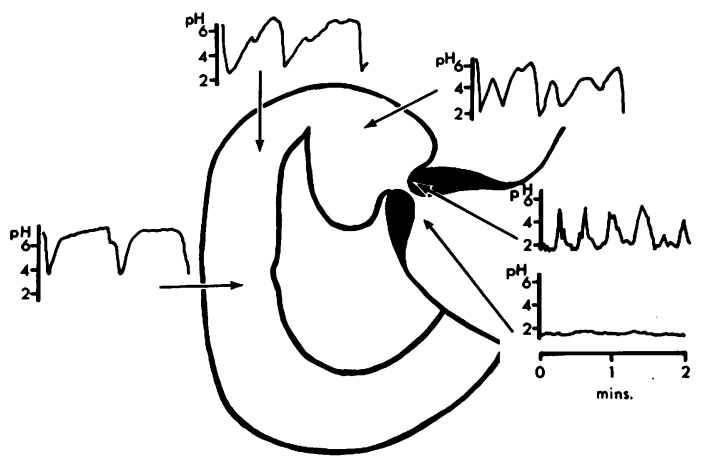

FIG. 3. Typical records of $\mathrm{pH}$ from the gastric antrum and different sites in the duodenum. 


\section{RESULTS}

In the antrum the $p \mathrm{H}$ was always steady in marked contrast to the duodenum where there were fluctuations. The $p \mathrm{H}$ records also differed at different sites in the duodenum (Fig. 3). At the very base of the bulb acidity was interrupted by neutrality, whereas beyond the apex of the bulb a neutral $p \mathrm{H}$ was interrupted by acid swings; in the middle of the bulb the $p \mathrm{H}$ fluctuated approximately evenly between acidity and neutrality. Occasionally, however, the $p \mathrm{H}$ of the second part of the duodenum continued to fluctuate evenly between acidity and neutrality in some patients with duodenal ulcer.

The results of $p \mathrm{H}$ recorded from the various sites in normal subjects and in patients with duodenal ulcer are shown in Tables II and III. The results from the two groups were compared. They had been obtained during a similar period after the meal (in normal subjects from $58.2 \pm 4.6 \mathrm{~min}$. to $100 \pm 6.4$ min. and in the subjects with ulcer from $63 \cdot 7 \pm 6 \cdot 8$ min. to $98.2 \pm 5.5 \mathrm{~min}$.); $p \mathrm{H}$ was recorded from each site for between five and 20 minutes.

In the antrum the average $p \mathrm{H}$ was lower than normal in half of the duodenal ulcer group (Fig. 4).

THE AVERAGE DUODENAL $p \mathrm{H}$ No difference was found between the average duodenal $p \mathrm{H}$ in the two groups of subjects. In both groups of subjects there was an increase of $p \mathrm{H}$ from the base of the duodenal bulb to the second part of the duodenum. Moreover, in the bulb itself, there was a gradual increase in $p \mathrm{H}$ from the base to the apex (Fig. 4). Thus, the average $p \mathrm{H}$ of all subjects in the middle bulb segment $(p \mathrm{H}$ 4.2 ) was 0.9 units less than the average $p \mathrm{H}$ at the

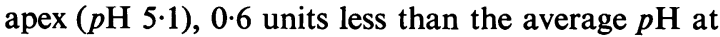
the distal half of the bulb $(p \mathrm{H} \mathrm{4.8)}$ and 0.9 units more than that at the base of the bulb $(p \mathrm{H} \mathrm{3 \cdot 3})$.

THE DURATION OF LOW LEVELS OF $p H$ The length of

TABLE II

AVERAGE $p$ H AND PERCENTAGE OF TIME $p$ H WAS LESS THAN 2, 2.5, AND 3 FOR DIFFERENT SITES IN THE DUODENUM FOR NORMAL SUBJECTS

\begin{tabular}{|c|c|c|c|c|c|c|c|c|c|c|c|c|c|c|c|c|c|c|c|c|c|c|c|c|c|c|c|}
\hline \multicolumn{4}{|c|}{ Base Bulb } & \multicolumn{4}{|c|}{ Middle Bulb } & \multicolumn{3}{|c|}{$\begin{array}{l}\text { Distal Half of } \\
\text { Bulb }\end{array}$} & \multicolumn{4}{|c|}{ Apex Bulb } & \multicolumn{5}{|c|}{$\begin{array}{l}\text { Upper Third of } \\
\text { Second Part }\end{array}$} & \multicolumn{3}{|c|}{$\begin{array}{l}\text { Middle Third of } \\
\text { Second Part }\end{array}$} & \multicolumn{5}{|c|}{$\begin{array}{l}\text { Lower Third of } \\
\text { Second Part }\end{array}$} \\
\hline$A v$ & $<2$ & $<2 \cdot 5$ & $<3$ & $A v$ & $<2$ & $<2 \cdot 5$ & $<3$ & $A v$ & $<2$ & $<2 \cdot 5$ & $<3$ & $A v$ & $<2$ & $<2 \cdot 5$ & $<3$ & $A v$ & $<2$ & $<2 \cdot 5$ & $<3$ & $A v$ & $<2$ & $<2 \cdot 5$ & $<3$ & $A v$ & $<2$ & $<2 \cdot 5$ & $<3$ \\
\hline & & & & $3 \cdot 8$ & 0 & 0 & 0 & $4 \cdot 1$ & 0 & 5 & 19 & $5 \cdot 3$ & 0 & 0 & 3 & 6.6 & 0 & 0 & 1 & & & & & $6 \cdot 2$ & 0 & 0 & 0 \\
\hline $2 \cdot 6$ & 0 & & 85 & $3 \cdot 4$ & 0 & 0 & 5 & & & & & $3 \cdot 8$ & 0 & 0 & 14 & & & & & $5 \cdot 4$ & 0 & 0 & 0 & & & & \\
\hline $3 \cdot 2$ & 4 & 16 & 38 & $3 \cdot 8$ & 1 & 11 & 23 & & & & & & & & & & & & & $6 \cdot 2$ & 1 & 1 & 1 & $5 \cdot 7$ & 0 & 0 & 0 \\
\hline $3 \cdot 8$ & 0 & 1 & 17 & & & & & $3 \cdot 7$ & 1 & $5 \cdot 4$ & 22 & $5 \cdot 7$ & 0 & 0 & 0 & $4 \cdot 4$ & 0 & & 11 & & & & & $7 \cdot 0$ & 0 & 0 & 0 \\
\hline $2 \cdot 5$ & 32 & & 81 & $4 \cdot 4$ & 3 & 4 & 7 & & & & & $6 \cdot 8$ & 0 & 0 & 0 & & & & & & & & & 6.6 & 0 & 0 & 1 \\
\hline $5 \cdot 1$ & 2 & 4 & 6 & $4 \cdot 5$ & 0 & 2 & 9 & $5 \cdot 7$ & 0 & 2 & 5 & $4 \cdot 2$ & 3 & 5 & 21 & $5 \cdot 4$ & 2 & & 5 & & & & & & & & \\
\hline $2 \cdot 4$ & 39 & & 77 & $4 \cdot 2$ & 0 & 1 & 10 & $5 \cdot 2$ & 1 & 2 & 6 & 6.4 & 0 & 0 & 0 & 6.4 & 0 & 0 & 1 & & & & & & & & \\
\hline & & & & $4 \cdot 1$ & 0 & 4 & 14 & $3 \cdot 5$ & 0 & 5 & 30 & $5 \cdot 8$ & 0 & 0 & 1 & & & & & 6 & 0 & 0 & 0 & $6 \cdot 2$ & 0 & 0 & 0 \\
\hline & & & & & & & & & & & & $7 \cdot 1$ & 0 & 0 & 0 & $7 \cdot 0$ & 0 & 0 & 0 & $7 \cdot 8$ & 0 & 0 & 0 & $7 \cdot 4$ & 0 & 0 & 0 \\
\hline $\begin{array}{l}3 \cdot 8 \\
4 \cdot 5\end{array}$ & $\begin{array}{l}0 \\
0\end{array}$ & 6 & $\begin{array}{l}22 \\
13\end{array}$ & $5 \cdot 6$ & 0 & & 1 & 5.9 & 0 & 0 & 0 & $\begin{array}{l}6 \cdot 3 \\
5 \cdot 0\end{array}$ & $\begin{array}{l}0 \\
1\end{array}$ & $\begin{array}{l}0 \\
4\end{array}$ & $\begin{array}{r}0 \\
11\end{array}$ & $5 \cdot 6$ & 0 & 0 & 1 & & & & & $6 \cdot 2$ & 0 & & 1.4 \\
\hline
\end{tabular}

\section{TABLE III}

AVERAGE $p$ H AND PERCENTAGE OF TIME $p$ H WAS LESS THAN $2,2 \cdot 5$, AND 3 FOR DIFFERENT SITES IN THE DUODENUM FOR ULCER SUBJECTS

\begin{tabular}{|c|c|c|c|c|c|c|c|c|c|c|c|c|c|c|c|c|c|c|c|c|c|c|c|c|c|c|c|c|}
\hline \multirow[t]{2}{*}{$\begin{array}{l}\text { iubject } \\
\text { Vumber }\end{array}$} & \multicolumn{4}{|c|}{ Base Bulb } & \multicolumn{4}{|c|}{ Middle Bulb } & \multicolumn{3}{|c|}{$\begin{array}{l}\text { Distal Half of } \\
\text { Bulb }\end{array}$} & \multicolumn{5}{|c|}{ Apex Bulb } & \multicolumn{4}{|c|}{$\begin{array}{l}\text { Upper Third of } \\
\text { Second Part }\end{array}$} & \multicolumn{4}{|c|}{$\begin{array}{l}\text { Middle Third of } \\
\text { Second Part }\end{array}$} & \multicolumn{4}{|c|}{$\begin{array}{l}\text { Lower Third of } \\
\text { Second Part }\end{array}$} \\
\hline & $A v$ & $<2$ & $<2 \cdot 5$ & $<3$ & $A v$. & $<2$ & $<2 \cdot 5$ & $<3$ & $A v$. & $<2$ & $<2 \cdot 5$ & $<3$ & $A v$ & $<2$ & $<2.5$ & $<3$ & $A v$ & $<2$ & $<2 \cdot 5$ & $<3$ & $A v$. & $<2$ & $<2 \cdot 5$ & $<3$ & $A v$ & $<2$ & $<2 \cdot 5$ & $<3$ \\
\hline 1 & $4 \cdot 1$ & 11 & & 13 & & & & & $6 \cdot 5$ & 0 & 0 & 0 & & & & & & & & & $5 \cdot 8$ & 0 & 0 & 0 & & & & \\
\hline 2 & $3 \cdot 2$ & 3 & & 49 & $4 \cdot 3$ & 2 & 4 & 8 & & & & & $5 \cdot 2$ & 1 & 2 & 5 & & & & & & & & & & & & \\
\hline 3 & $3 \cdot 1$ & 1 & & 45 & $5 \cdot 5$ & 0 & 0 & 1 & & & & & $4 \cdot 5$ & 1 & 3 & 10 & & & & & & & & & & & & \\
\hline 4 & $2 \cdot 7$ & 23 & & 66 & & & & & $4 \cdot 1$ & 1 & 5 & 39 & $4 \cdot 9$ & 2 & 3 & 9 & 5.4 & 0 & & 1.9 & $5 \cdot 4$ & 1 & & $7 \cdot 4$ & $6 \cdot 3$ & 0 & & 1 \\
\hline 5 & & & & & & & & & & & & & & & & & $7 \cdot 0$ & 0 & 0 & 0 & 7.0 & 0 & 0 & 0 & 7,0 & 0 & 0 & 0 \\
\hline 6 & $2 \cdot 8$ & 13 & & 71 & $3 \cdot 3$ & 8 & 12 & 30 & & & & & $3 \cdot 8$ & 21 & 29 & 35 & & & & & & & & & & & & \\
\hline 7 & & & & & $4 \cdot 4$ & 15 & 23 & 29 & $5 \cdot 2$ & 4 & 15 & 24 & & & & & 6.9 & $3 \cdot 3$ & & 7 & 6.4 & 0 & & 7 & $7 \cdot 2$ & 0 & 0 & 1 \\
\hline 8 & $2 \cdot 6$ & 9 & 39 & 66 & $4 \cdot 0$ & 4 & 13 & 28 & $3 \cdot 2$ & 3 & 20 & 33 & 3.9 & 0 & 10 & 25 & & & & & & & & & $5 \cdot 4$ & 0 & 0 & 0 \\
\hline 9 & & & & & & & & & $4 \cdot 2$ & 6 & 11 & 20 & & & & & & & & & $6 \cdot 3$ & 0 & 0 & 0 & $6 \cdot 1$ & 0 & 0 & 0 \\
\hline 10 & & & & & & & & & & & & & $2 \cdot 8$ & 45 & 59 & 70 & & & & & $5 \cdot 1$ & 14 & & 27 & 5.8 & 1.5 & & 10 \\
\hline 11 & & & & & $5 \cdot 2$ & 1 & 2 & 4 & & & & & $4 \cdot 8$ & 0 & 1 & 4 & 6.3 & 0 & 0 & 0 & & & & & & & & \\
\hline 12 & & & & & $4 \cdot 2$ & 0 & 11 & 29 & 6.7 & 0 & 0 & 0 & 6 & 0 & $i$ & 3 & & & & & & & & & & & & \\
\hline 13 & & & & & $2 \cdot 8$ & 18 & 28 & 62 & & & & & 3.9 & 1 & 11 & 21 & $2 \cdot 3$ & 46 & 71 & 81 & & & & & & & & \\
\hline
\end{tabular}




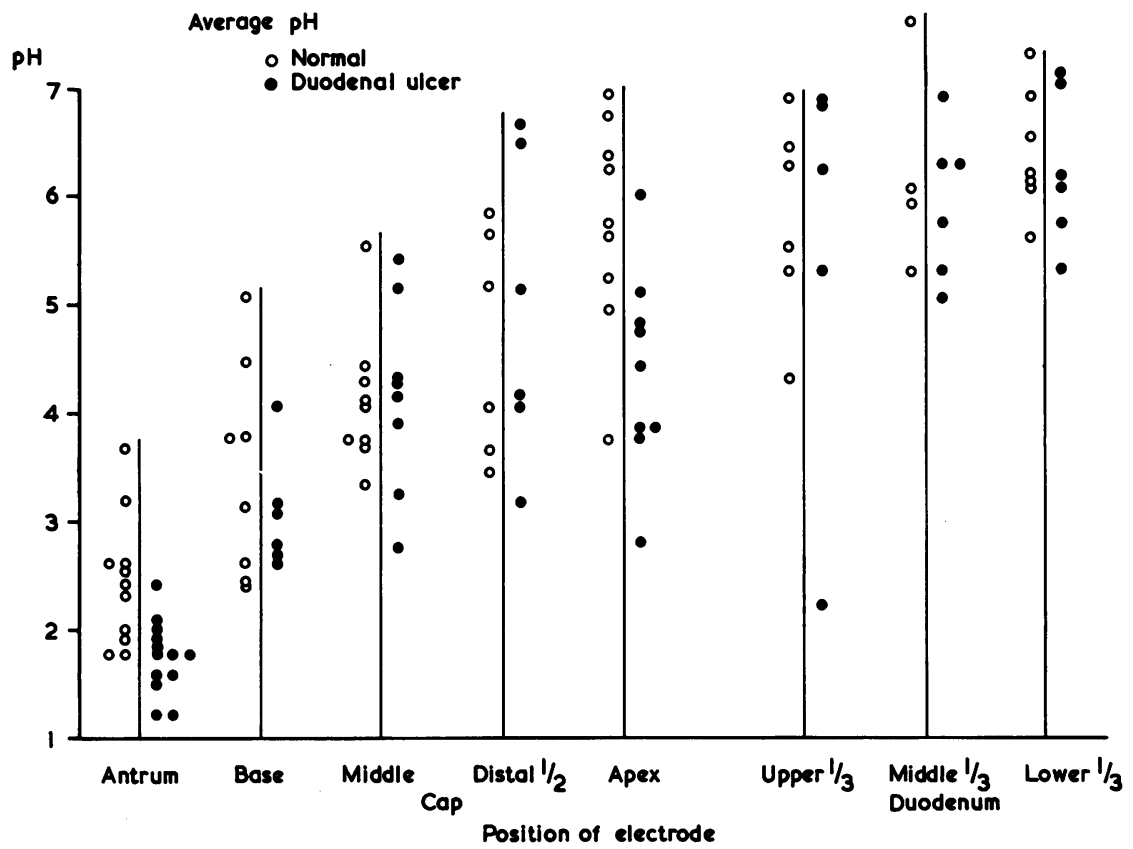

Duodenal pH

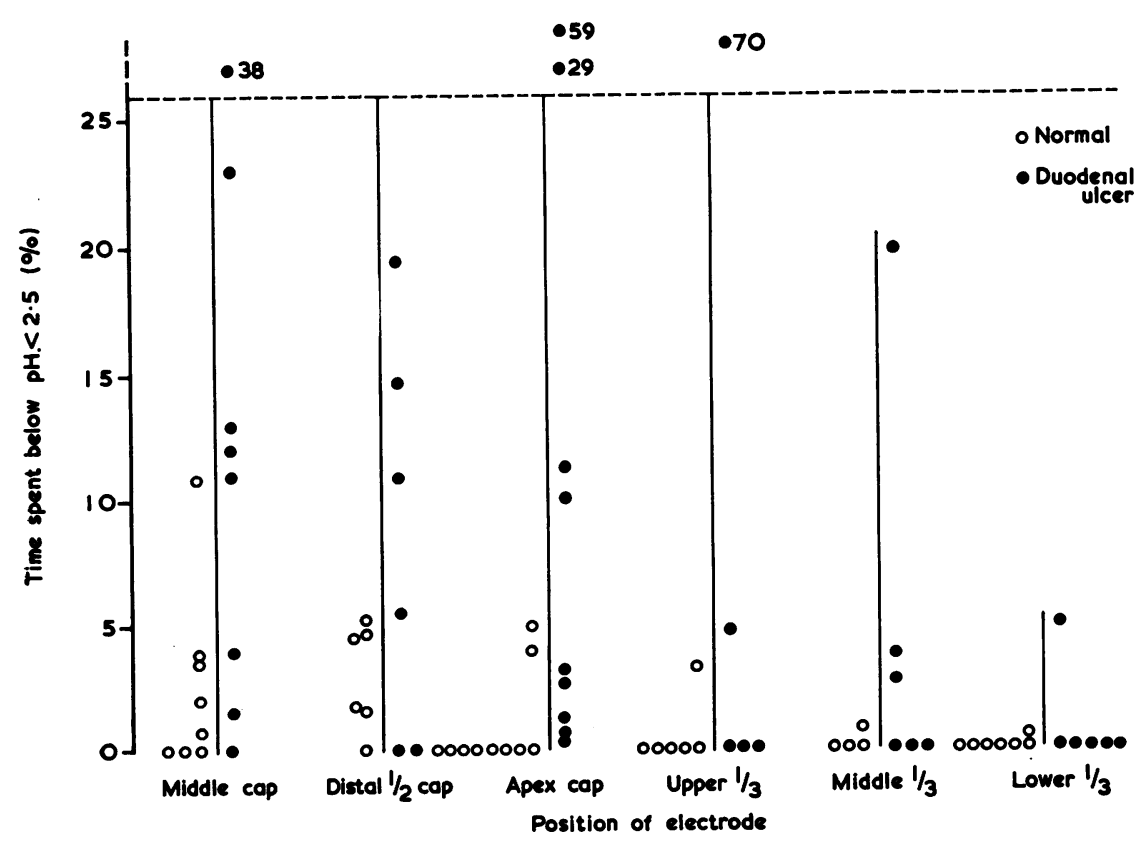

FIG. 4. The average $\mathrm{pH}$ at different sites in normal and ulcer subjects.

FIG. 5. The percentage of time spent below $\mathrm{pH}$ 2.5 at different sites in normal and duodenal ulcer subjects (values greater than $26 \%$ are not on the same scale). 


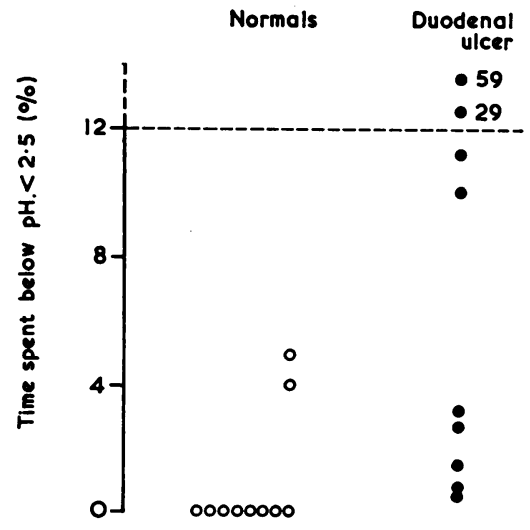

FIG. 6. The percentage of time spent below $\mathrm{pH} 2.5$ at apex of the duodenal bulb in normal and ulcer subjects. (The values greater than $12 \%$ are not given on the same scale.)

time spent below $p \mathrm{H} 2.5$ at different sites in the duodenum is given in Figure 5. There is a difference between the two groups at each site, which is most marked at the apex of the bulb (Fig. 6). Results are available from this site in 10 normal subjects and in nine with duodenal ulcer. In eight of the 10 normal subjects the $p \mathrm{H}$ did not fall below 2.5 whereas in all of the subjects with duodenal ulcer it was less than 2.5 at some time. The results in Fig. 5 again show a difference between the acidity of the contents of the bulb and that of the second part of the duodenum. In the bulb the $p \mathrm{H}$ fell below 2.5 in 32 of 46 records, whereas in the second part of the duodenum it fell below 2.5 in only nine of 34 records.

POST-BULBAR ULCER Subject D.U.13 deserves special consideration. In this patient the ulcer was distal to the bulb in a segment which was narrowed, either by spasm or fibrosis. Records of $p \mathrm{H}$ from the duodenal bulb were similar to those usually seen in the gastric antrum (Fig. 7), viz., they were acid, with very few fluctuations, but in the post-bulbar section fluctuations were common.

\section{DISCUSSION}

The difficulties involved in the measurement of duodenal bulb acidity and the limitations of previous studies have been discussed fully by Rhodes $e t$ al. (1966). There is little information available concerning acidity at different sites in the duodenum. Rovelstad and Maher (1962) were unable to show a difference between $p \mathrm{H}$ in the bulb and the second part of the duodenum. Birchner, Mann, Carlson, Code, and Rovelstad (1965) have recently measured $p \mathrm{H}$ in the proximal duodenum with two electrodes. In the duodenal bulb a guarded electrode recorded a steady $p \mathrm{H}$ about 2 , whereas beyond the bulb there were fluctuations of $p \mathrm{H}$. Our results show that in both normal subjects and patients with duodenal ulcer, there is a steep gradient of $p \mathrm{H}$ between the base of the duodenal bulb and the second part of the duodenum. The presence of this gradient makes it essential to know the precise position of the electrode in the bulb, if the results from different subjects are to be compared.

One criticism of these investigations is that the electrodes may have moved to and fro while $p \mathrm{H}$ was recorded. However, the position of the electrode was checked repeatedly and since the recording periods were short, it seems unlikely that serious error could

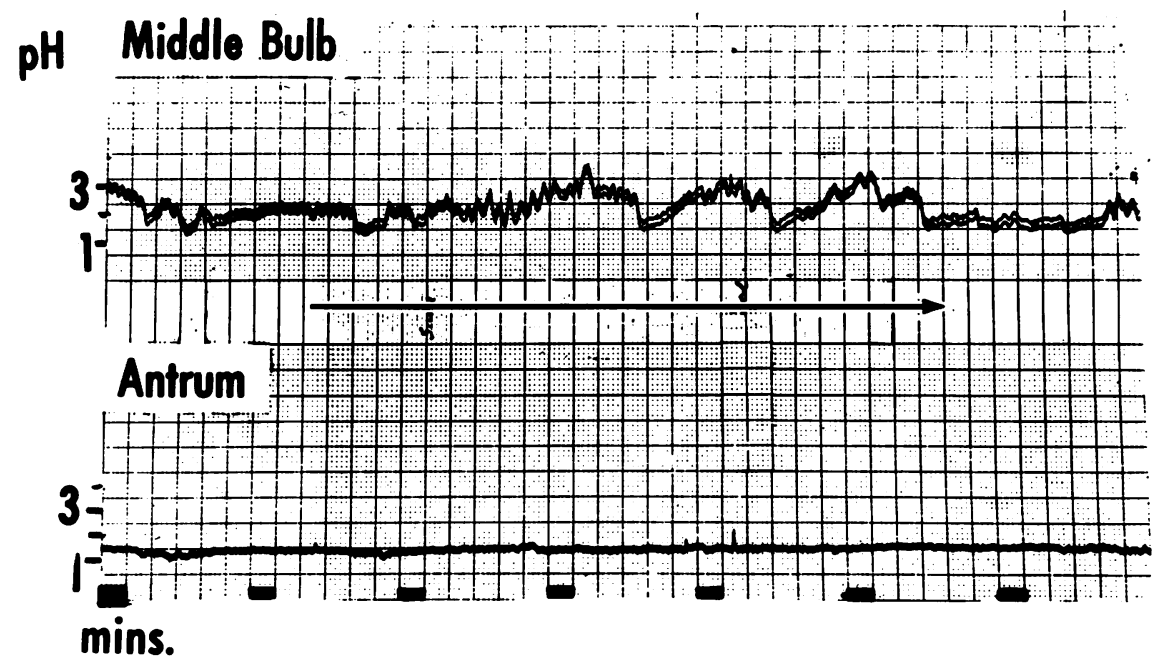

FIG. 7. The $\mathrm{pH}$ record from a subject with a post-bulbar duodenal ulcer. There are no wide fluctuations of $\mathrm{pH}$ in the bulb. 
have been caused by movement of the electrodes. It was impossible to obtain a constant rate of gastric emptying in all subjects. Attempts were made to overcome this difficult problem: the subjects had a standard meal, $p \mathrm{H}$ was recorded during the same period after food, and the subjects were placed in a position which facilitated gastric emptying. To avoid gross differences in gastric emptying in different subjects affecting the results, records which did not have regular fluctuations of duodenal $p \mathrm{H}$ were discarded. While $p \mathrm{H}$ was recorded at different sites in the duodenum, the frequency of fluctuations of $p \mathrm{H}$ varied because of small irregularities in gastric emptying. Because of these irregularities there was not invariably a progressive rise in $p \mathrm{H}$ between the base of the bulb and the second part of the duodenum; thus in patient D.U.13 the mean $p \mathrm{H}$ in the second part of the duodenum was lower than that in the bulb.

Measurement of the length of time spent below certain levels of $p \mathrm{H}$ and the area below the $p \mathrm{H}$ tracing allows one to analyse the tracings in detail. The analyses of duodenal bulb $p \mathrm{H}$, in normal and ulcer subjects, show a difference between the groups, but the most marked difference was found on measuring the length of time spent below $p \mathrm{H} 2.5$ at the apex of the bulb.

The difference in the length of time spent at low levels of $p \mathrm{H}$ in the two groups could be due to several factors, namely, the gastric contents in subjects with ulcer are more acid than normal. The volume of gastric acid entering the duodenum in subjects with ulcer is greater than normal. The ability of subjects with ulcer to neutralize acid in the duodenal bulb is less than normal.

The mean antral $p \mathrm{H}$ was lower in the group of subjects with ulcer than in the normal group, and Levin, Kirsner, Palmer, and Butler (1948) have shown that subjects with duodenal ulcer secrete greater volumes of gastric acid than normal. Inadequate neutralization of the contents of the bulb may occur in subjects with ulcer either because the bulb is scarred or spastic; both abnormalities could prevent the reflux of alkaline juice into the duodenal bulb.

The difference between the results in the two groups was not due to a difference in age as there were more elderly patients in the ulcer group, and it is known that gastric acid secretion is less in older people (Levin et al., 1948).
Since acid enters the duodenum at the pylorus and alkali in the second part of the duodenum, it is inevitable that there will be a steep increase of $p \mathrm{H}$ in the proximal part of the duodenum. The $p \mathrm{H}$ tracings from the duodenum suggest that gastric contents are neutralized chiefly in the bulb before reaching the second part of the duodenum, presumably as a result of reflux of alkaline content.

The difference in the acidity of the contents of the duodenal bulb in normal and ulcer subjects (Fig. 5) supports the hypothesis that duodenal ulcer is associated with a high duodenal acidity.

\section{SUMMARY}

The $p \mathrm{H}$ was measured at different sites in the duodenum for short periods during which the position of the electrode was controlled radiologically. Normal subjects and patients with duodenal ulcer were examined.

Striking differences in $p \mathrm{H}$ were observed in different parts of the duodenum. Adjacent to the pylorus the $p \mathrm{H}$ was predominantly acid whereas in the second part of the duodenum it was predominantly neutral. Moreover there was a steep gradient of $p \mathbf{H}$ across the first part of the duodenum. In the middle of the bulb the fluctuations of $p \mathrm{H}$ were unlike those seen elsewhere in the duodenum; here the $p \mathrm{H}$ often fluctuated, approximately equally between extremes of acidity and neutrality.

In patients with duodenal ulcer the acidity tended to be high at all sites in the duodenum for a greater proportion of the time than in normal subjects.

We are grateful to Professor H. Scarborough and Dr. A. H. James for their help and encouragement, to Mr. C. E. Rossiter for help with the statistics, and to Mr. R. Marshall for preparing the illustrations. The work was carried out while J. Rhodes was the Cardiff Royal Infirmary Research Fellow in Medicine.

\section{REFERENCES}

Birchner, J., Mann, C. V., Carlson, H. C., Code, C. F., and Rovelstad, R. A. (1965). Intraluminal and juxtamucosal duodenal $p H$. Gastroenterology, 48, 472-477.

Levin, E., Kirsner, J. B., Palmer, W. L., and Butler, C. (1948). Nocturnal gastric secretion. Arch. Surg., 56, 345-356.

Rhodes, J., Apsimon, H. T., and Lawrie, J. H. (1966). The $p H$ of the contents of the duodenal bulb in relation to duodenal ulcer. Gut, 7, 502.

Rovelstad, R. A., and Maher, F. T. (1962). Problems associated with assessment of the effects of diet, antacids, and anticholinergic agents on gastric and duodenal acidity, as measured by the glass electrode in situ. Gastroenterology, 42, 588-594. 